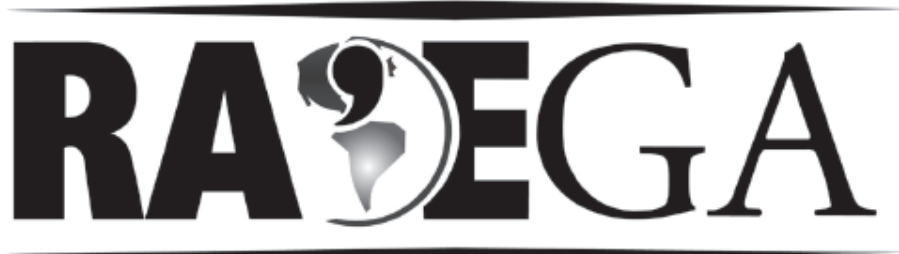

O ESPAÇO GEOGRÁFICO EM ANÁLISE

\title{
GEODIVERSIDADE E POTENCIAL GEOTURÍSTICO DO SALTO DE FURNAS - INDIANÓPOLIS-MG
}

\section{GEODIVERSITY AND TOURISTIC POTENTIAL OF SALTO DE FURNAS - INDIANÓPOLIS-MG}

\author{
Lilian Carla Moreira BENTO $^{1}$ \\ Sílvio Carlos RODRIGUES ${ }^{2}$
}

\section{RESUMO}

Indianópolis está localizado na mesorregião do Triângulo Mineiro e é reconhecido pela beleza de suas inúmeras quedas d'água. Esses atributos nos levaram a estudar tal município, buscando identificar o potencial de suas quedas para um novo segmento turístico de base natural, o geoturismo. Neste estudo apresentamos a geodiversidade e o potencial geoturístico de apenas uma das 20 quedas encontradas no município (Salto de Furnas), devido a algumas particularidades, como diversidade litológica, grau de preservação, facilidade de acesso, proximidade do perímetro urbano, entre outros. Para tanto, foi realizada pesquisa bibliográfica sobre a temática em questão e de trabalhos voltados à caracterização da geodiversidade local, enfatizando os aspectos geológicos e geomorfológicos; trabalhos de campo visando o georreferenciamento e medição do tamanho da queda e registro fotográfico e, ao final, trabalhos de gabinete, momento no qual os dados foram interpretados e relacionados, gerando as informações aqui expostas. Diante desta metodologia conclui-se que o Salto de Furnas, assim como outras quedas

\footnotetext{
${ }^{1}$ Doutoranda em Geografia pela Universidade Federal de Uberlândia - liliancmb@yahoo.com.br

${ }^{2}$ Profo Dro Instituto de Geografia da Universidade Federal de Uberlândia - silgel@ufu.br
} 
localizadas em Indianópolis, apresenta uma geodiversidade rica, bela e de grande valor científico, didático e turístico, sendo local propício para a implantação do geoturismo.

Palavras-chave: Diversidade. Patrimônio natural abiótico. Turismo de base natural. Geoconservação. Quedas d'água.

\section{ABSTRACT}

Indianopolis is located in the mesoregion of Triangulo Mineiro and is recognized by the beauty of its many waterfalls. These attributes led us to study the municipalityl, seeking to identify the potential of the falls for a new tourist segment with natural basis: the geotourism. In this sttudy is presented the geodiversity and the geotouristic potential of only one of 20 falls located in the municipality (Salto de Furnas), due to some particularities, as lithological diversity, preservation level, acess facility, proximity of the city limits, among others. For this, bibliographical research on the subject in question and works related to the characterization of local geodiversity was carried out with emphasis on geological and geomorphological, measurement and pictures were done.At the end of the research, cabinet works were done to make interpretation and correlation of the data here exposed. Given this approach it is concluded that the Salto de Furnas as well as other falls located in Indianapolis, presents a rich, beautiful and valuable geodiversity features, with scientific, educational and tourism value and being a suitable place for the deployment of geotourism.

Key-words: Diversity, abiotic natural heritage, natural basic tourism, geoconservation, waterfalls.

\section{INTRODUÇÃO}

O turismo vem se destacando na atualidade como uma das atividades de maior crescimento, sendo as áreas naturais os atrativos mais procurados pelos turistas, refletindo, entre outros, a expansão dos meios de transporte, a deteriorização da qualidade de vida urbana, a maior preocupação com as questões ambientais etc.

A busca por áreas naturais faz expandir o mercado turístico baseado em segmentos como o turismo rural, o turismo de aventura, o ecoturismo e, mais recentemente, o geoturismo, o que é conseqüência do surgimento de uma 
nova tendência mundial em que as pessoas tentam suprir suas deficiências e esquecer seus problemas tendo contato com um meio ambiente natural sadio, harmônico, autêntico, belo e que the provoque sensações de paz, contentamento, pertencimento, direcionamento, conhecimento, entre outras.

Nesse sentido, tem sido criados segmentos para suprir essa nova demanda, bem como para preencher lacunas existentes em outros segmentos turísticos. Este é o caso do geoturismo, segmento que surge a partir da década de 1990 e que, em linhas gerais, completa o ecoturismo no sentido que sua visitação baseia-se na apreciação e entendimento dos aspectos abióticos da paisagem.

As quedas d'água são relevantes atrativos geoturísticos não só pela sua beleza cênica, mas também pela possibilidade de explicação da história geológica através de seu perfil litoestratigráfico, assim como de sua gênese, fazendo com que o turista tenha a oportunidade de aprender um pouco sobre a geologia e relevo locais, tornando-se potenciais multiplicadores da importância da geoconservação de locais como estes que são verdadeiras páginas da evolução do planeta Terra.

Diante disso, o objetivo do presente estudo foi refletir sobre o potencial geoturístico do Salto de Furnas a partir da caracterização de sua geodiversidade, de forma a criar argumentos que justifiquem a necessidade de sua divulgação e geoconservação, bem como de sua inserção em projetos de planejamento turístico.

\section{GEOTURISMO - UM CONCEITO EM CONSTRUÇÃO}

O geoturismo surgiu nos países desenvolvidos, alastrando-se atualmente para outras partes do mundo. Por esse motivo grande parte de referências relacionadas a esse segmento turístico está em língua estrangeira, destacando-se as obras de Boivin (1990), Dixon (1996), Carvalho (1999), Patzak (2001), Garofano (2003), Brilha (2005), Dowling e Newsome (2005) etc. 
O surgimento desse novo segmento turístico, que é por muitos autores considerado um sub-segmento do ecoturismo, está relacionado, em linhas gerais, com a necessidade de entendimento das áreas visitadas por parte dos turistas e com a possibilidade de divulgação e valorização de aspectos representativos da história geológica da Terra, bem como sua evolução geomorfológica.

O primeiro conceito relacionado ao geoturismo foi criado em 1995 por Thomas Hose, o mesmo o redefinindo e aprimorando em 2000, sendo "[...] a provisão de facilidades interpretativas e serviços para promover os benefícios sociais de lugares e materiais geológicos e geomorfológicos e assegurar sua conservação, para uso de estudantes, turistas e outras pessoas com interesse recreativo ou de lazer" (HOSE, 2000 apud LEITE DO NASCIMENTO; RUCHKYS; MANTESSO-NETO, 2007, p. 5, grifo nosso).

O geoturismo está relacionado, portanto, com os aspectos geológicos e geomorfológicos e pode ter, basicamente, três motivações: recreação, lazer e aprendizado, todos contribuindo para a conservação de atrativos como quedas d'água, cavernas, afloramentos rochosos, serras, vulcões, jazidas de minerais, cânions, entre outros.

O geoturismo deve ser entendido como o segmento turístico que tem sua visitação baseada na contemplação e entendimento da geodiversidade, enquanto que o ecoturismo se baseia na biodiversidade.

Em 2007 Ruchkys defendeu sua tese sobre patrimônio geológico e geoconservação do Quadrilátero Ferrífero e nela conceituou geoturismo como sendo

[...] um segmento da atividade turística que tem o patrimônio geológico como seu principal atrativo e busca sua proteção por meio da conservação de seus recursos e da sensibilização do turista, utilizando, para isto, a interpretação deste patrimônio tornando-o acessível ao público leigo, além de promover a sua divulgação e o desenvolvimento das Ciências da Terra (RUCKHYS, 2007, p. 23).

Nesse mesmo ano Silva e Perinotto também definiram geoturismo como 
passado ou da história da origem e evolução do planeta Terra. Também se inclui, nesse contexto, o conhecimento científico sobre a gênese da paisagem, os processos envolvidos e os testemunhos registrados em rochas, solos e relevos (SILVA; PERINOTTO, 2007, não paginado).

Leite do Nascimento, Schobbenhaus e Medina (2009), explicam que o geoturismo tem por objetivo preencher uma lacuna do ponto de vista da informação, possibilitando ao turista não só contemplar as paisagens, como entender os processos geológicos e geomorfológicos responsáveis por sua formação.

Se os objetivos do geoturismo não são meramente contemplativos e apresentam uma finalidade didática podemos associá-lo à educação ambiental. Esse é o posicionamento de Geremia et al (2004 apud SILVA, 2007, p. 35) que afirmam que o geoturismo "[...] possibilita a interpretação da herança natural da paisagem quando se desfruta e reconhece as suas particularidades geológicas e geomorfológicas".

Reynard e Pralong (2004 apud SILVA, 2007, p. 35), frisam que "[...] a problemática do geoturismo inscreve-se no campo do turismo didático, por constituir uma nova forma que oferece instrumentos de interpretação que permitem dialogar e compreender os sítios visitados ou descobertos".

Leite do Nascimento, Ruchkys e Mantesso-Neto (2008, p. 43), ressaltam a questão da interpretação, argumentando que é ferramenta indispensável para "[...] sensibilizar as pessoas sobre a importância do patrimônio e despertar o desejo de contribuir para sua conservação".

Inferimos, diante da riqueza de conceitos existentes, que o geoturismo é um segmento turístico que veio preencher uma lacuna do ecoturismo, dando atenção aos fatores abióticos da paisagem como elementos geológicos e/ou geomorfológicos, buscando sua apreciação, interpretação e conservação e é considerado em construção, pois ainda está sendo reelaborado com a contribuição de estudiosos de todo o mundo que têm começado a se interessar por essa temática.

Apesar de recente na literatura brasileira já é possível encontrar diversos trabalhos científicos que buscam retratar o potencial geoturístico de alguns locais desse imenso território dotado de grande diversidade biótica e abiótica 
que é o Brasil, entre eles podemos citar a dissertação de Barreto (2007) sobre o potencial geoturístico da região de Rio de Contas na Bahia, Silva (2007) com a dissertação "A paisagem do Quadrilátero Ferrífero, MG: Potencial para o uso turístico da sua geologia e geomorfologia", Silva (2004) com sua dissertação sobre a contribuição da geologia para o desenvolvimento sustentável do turismo na Estância Turística de Paraguaçu Paulista, Bento (2010) com seu mestrado sobre o potencial geoturístico das quedas d'água do município de Indianópolis/MG, entre muitos outros.

Isto sem mencionar a infinidade de trabalhos que têm sido apresentados em eventos científicos que cada vez mais abrem espaço para essa nova temática que é, na verdade, uma oportunidade de relacionar uma atividade econômica (turismo) com a ciência, possibilitando um aprendizado com grande potencial para a conservação de locais que têm sido negligenciados há muito tempo pela sociedade e meio acadêmico.

\section{GEODIVERSIDADE - CONHECER PARA VALORIZAR E CONSERVAR}

Apesar do termo geodiversidade ser pouco conhecido já sabe-se que sua origem está relacionada com a Conferência de Malvern sobre Conservação Geológica e Paisagística que ocorreu no Reino Unido em 1993 e segundo Pereira, Pereira, D. e Alves (2004) surge por comparação ao termo biodiversidade, sendo usado por geólogos e geomorfológos a partir da década de 1990.

Lima (2008) esclarece que muito conhecimento já foi gerado no campo da conservação da natureza, mas grande parte desses esforços foi direcionada a vertente biológica, o que gerou uma defasagem na evolução do conhecimento sobre a geodiversidade e sua importância para a evolução da vida na Terra.

Geodiversidade engloba "a variedade de ambientes geológicos, fenômenos e processos ativos geradores de paisagens, rochas, minerais, 
fósseis, solos e outros depósitos superficiais que constituem a base para a vida na Terra" (PATZAK, 2001 apud SILVA, 2007, p. 36, grifo nosso).

A geodiversidade está relacionada com a variedade de ambientes, fenômenos, processos e elementos abióticos da Terra, evidenciando tempos passados e atuais. Além disso, ela é resultado da interação de diversos fatores como as rochas, o clima, os seres vivos, entre outros, possibilitando o aparecimento de paisagens distintas em todo o mundo (BRILHA, 2005).

Considerando a ascensão desta temática no Brasil, o Serviço Geológico do Brasil criou uma definição própria para a geodiversidade, já incluindo a atribuição de valores para este tipo de diversidade. Segundo ela, geodiversidade deve ser entendida como

\begin{abstract}
[...] o estudo da natureza abiótica (meio físico) constituída por uma variedade de ambientes, composição, fenômenos e processos geológicos que dão origem às paisagens, rochas, minerais, águas, fósseis, solos, clima e outros depósitos superficiais que propiciam o desenvolvimento da vida na Terra, tendo como valores intrínsecos a cultura, o estético, o econômico, o científico, o educativo e o turístico (CPRM, 2006, não paginado).
\end{abstract}

Como se vê, a geodiversidade apresenta diversas categorias de valor, todas elas funcionando como uma mola propulsora para sua conservação e valorização, haja vista que é de suma importância para a manutenção do planeta Terra e para a humanidade.

Ao atribuir valores à geodiversidade abre-se caminho para o estabelecimento de locais com reconhecida importância, denominados de patrimônio geológico, devendo ser compreendidos como

[...] a ocorrência de um ou mais elementos da geodiversidade (afloramentos quer em resultado da acção de processos naturais quer devido à intervenção humana), bem como delimitados geograficamente e que apresente valor singular do ponto de vista científico, pedagógico, cultural, turístico ou outro (BRILHA, 2005, p. 52).

É importante esclarecer que apesar da terminologia patrimônio geológico, este na verdade é composto por um conjunto abrangente e 
complexo de diversos tipos de patrimônio, tais como o geomorfológico, petrológico, paleontológico, mineiro, tectônico, entre muitos outros.

Dentro do patrimônio geológico tem sido evidente a individualização do patrimônio geomorfológico e Forte (2008, p. 53) explica que isso se dá por três motivos principais

[...] necessidade de preservar a natureza e os seus elementos estruturantes, entre os quais se contam as geoformas; a procura de instrumentos de valorização social e econômica dos recursos naturais, tendo em vista actividades educativas, de lazer e de turismo ambiental, num contexto de desenvolvimento; o afirmar da geomorfologia enquanto área científica, que vê nesta temática um meio essencial de divulgação.

O patrimônio geomorfológico, também conhecido como sítio geomorfológico ou geomorfossítio engloba paisagens de grande beleza cênica, como chapadas, picos, quedas d'água, entre outras e designam o conjunto de formas de relevo e/ou depósitos correlativos de grande valor para a sociedade, principalmente valor científico (PEREIRA, 2006).

Panizza e Piacente (2008, p. 6), reforçam o conceito acima descrito, afirmando que um geomorfossítio

[...] is a landform with particular and significant geomorphological attributions, which qualify it as a component of a territory's cultural heritage (in a broad sense). The attributes that can confer value on a landform, making it an actual geomorphological asset, are: scientific, cultural, socioeconomic, scenic.

Os geomorfossítios são, enfim, áreas naturais onde os atributos principais estão relacionados à dinâmica geomorfológica, apresentando algum valor para a sociedade e sendo classificados em diferentes categorias temáticas considerando suas características litológicas, estruturais, elementos geomorfológicos, entre outros (PEREIRA et al, 2006): geoformas graníticas, vulcânicas, cársicas, residuais, culturais, fluviais, litorais, tectônicas, glaciárias..., sendo as quedas d'água, alvo deste artigo, um exemplo de geoforma fluvial. 
GEOCONSERVAÇÃO - INSTRUMENTO DE CONSERVAÇÃO DO PATRIMÔNIO NATURAL ABIÓTICO?

Segundo Gronggrijip (2000 apud LEITE DO NASCIMENTO; RUCHKYS; MANTESSO-NETO, 2008, p. 21), a "[...] geoconservação é um dos aspectos mais recentes da conservação da natureza", sendo uma forma de compatibilizar proteção e uso do patrimônio geológico, uma vez que ele

[...] - é um componente importante do Patrimônio Natural;

- representa uma importante herança cultural, de um caráter que não se repete;

- constitui uma base imprescindível para a formação de cientistas e profissionais;

- constitui um elemento de proteção de recursos estéticos e recreativos;

- serve para estabelecer uma ligação entre a história da Terra e a história dos homens e sua evolução biológica (GALLEGO; GARCIA, 1996 apud MOREIRA, 2008, p. 76-77).

O objetivo da geoconservação não é preservar toda a geodiversidade e muito menos todo o patrimônio natural abiótico, mas aquela parcela denominada de patrimônio geológico que apresente significativa relevância, podendo ser mantida a evolução natural dos aspectos geológicos e geomorfológico (SHARPLES, 2002 apud BRILHA, 2005).

Entre as diversas estratégias voltadas a geoconservação Brilha (2005) propõe uma metodologia de trabalho que envolve seis etapas: inventariação, quantificação, classificação, conservação, valorização e divulgação do patrimônio geológico e, por fim, o monitoramento de todo este processo (figura 01).

Na sua dissertação de mestrado Cumbe (2007) traz um vasto referencial sobre as estratégias e iniciativas mundiais voltadas a implementação da geoconservação, fazendo um rápido apanhado das metodologias usadas em localidades as mais variadas como Grã-Bretanha, Espanha, Itália, Irlanda e 
Portugal, sendo excelente referência para quem pretende aprofundar nessa temática.

A conservação dos aspectos geológicos e geomorfológicos tem como aliado o geoturismo, este sendo uma ótima oportunidade de promoção do patrimônio geológico, sensibilizando o público geral para a importância de sua conservação (LARWOODE; PROSSER, 1998, PATZAK, 2001 apud ARAÚJO, 2005).

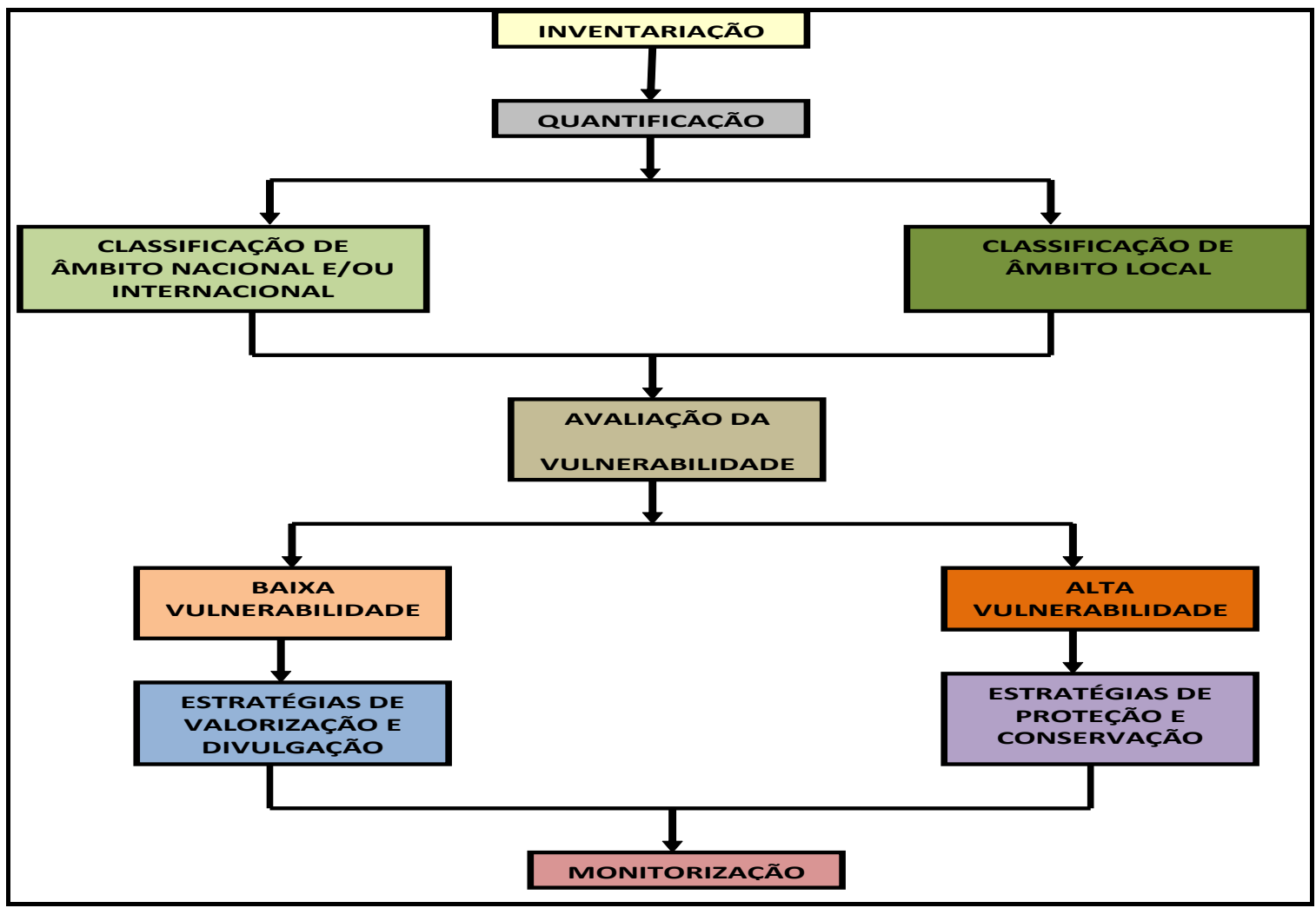

Figura 01: Fluxograma simplificado das fases de implementação das estratégias de geoconservação/Fonte: Adaptado de Brilha, 2005, p. 111.

O geoturismo pode promover a geoconservação bem como esta última pode promover o geoturismo, haja vista que ao proporcionar aos turistas uma visão mais científica do que contemplativa da paisagem o geoturismo acaba por possibilitar a promoção da geoconservação e esta, por sua vez, é ferramenta indispensável na conservação da geodiversidade mundial (figura 02): 


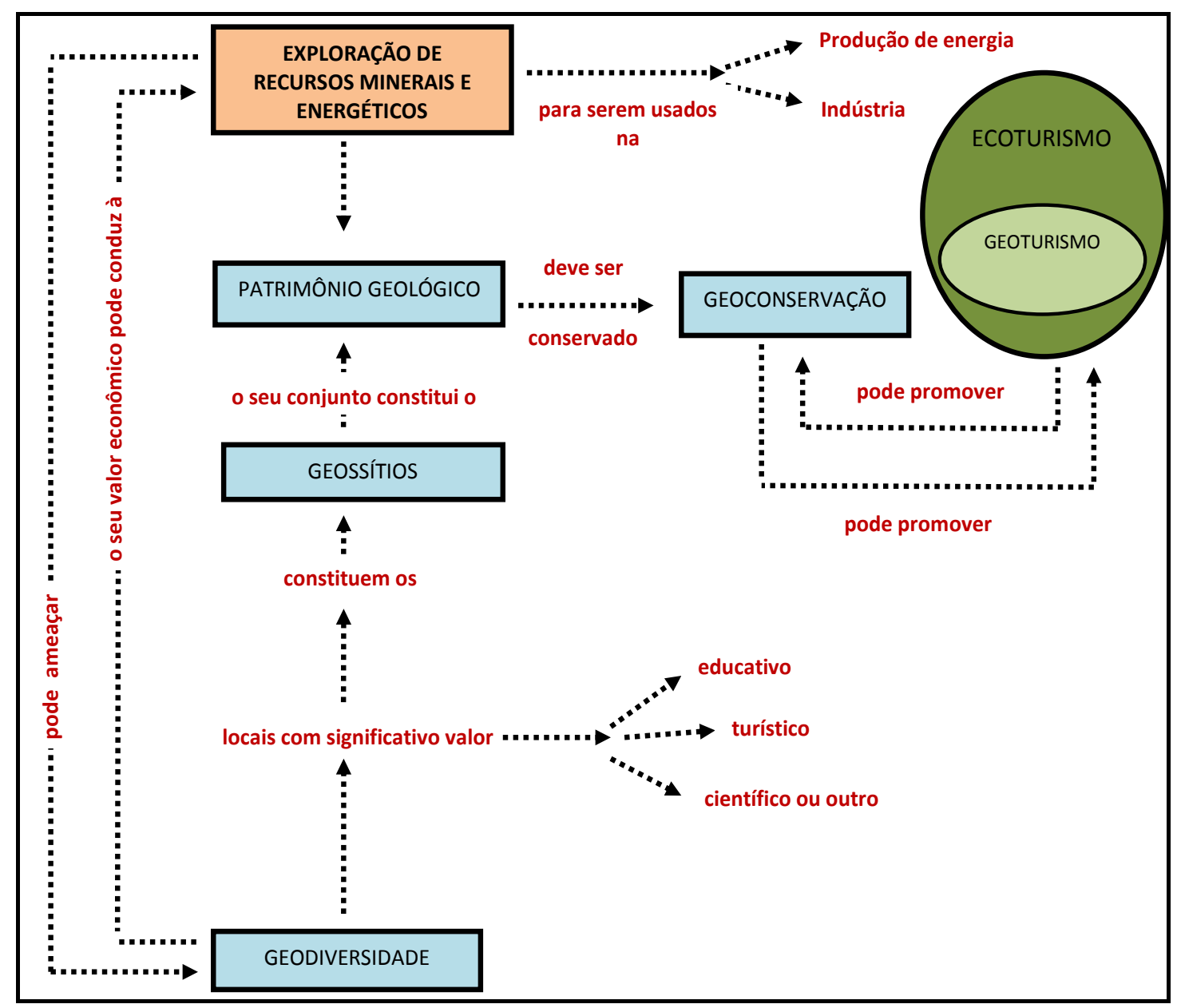

Figura 02: Mapa conceitual das relações entre a Geodiversidade, Geossítios, Patrimônio Geológico, Geoconservação e Geoturismo/Fonte: Adaptado de ARAÚJO, 2005, p. 41.

Nessa perspectiva, Rodrigues e Pereira (2009, p. 285-286) reforçam que [...] o patrimônio geológico pode ser um motivo de desenvolvimento das regiões, pois para além da sua importância cultural e científica, pode trazer benefícios turísticos, mobilizando as populações e aprofundando as relações entre essas e o seu território, as suas origens e os seus costumes. [...] Os roteiros geoturísticos [...] poderão vir a ser potencializadores do turismo e estimuladores da protecção do patrimônio em geral, dado que reúnem e interligam aspectos geológicos, geomorfológicos, arqueológicos e outros aspectos culturais, proporcionando assim o desenvolvimento de actividades sustentáveis. Estas actividades são desenvolvidas de forma a proporcionar aos visitantes não apenas momentos de lazer $e$ contemplação, mas também momentos de aprendizagem. 


\section{MÉTODO APLICADO}

Os procedimentos metodológicos utilizados para atingir os objetivos aqui propostos foram três: revisão bibliográfica, trabalhos de campo e trabalhos de gabinete.

A revisão bibliográfica incluiu o levantamento, localização, leitura e fichamento de obras pertinentes ao tema, de forma a se obter conceitos, explicações, modelos teóricos e metodologias existentes sobre a temática aqui abordada.

Os trabalhos de campo tiveram dois objetivos principais localizar a quedas d'água presentes no município, momento em que se identificava seus aspectos litoestratigráficos e tecia comentários sobre as possíveis explicações para a gênese e evolução das quedas.

Nesta etapa coletava-se as coordenadas geográficas de cada queda localizada através de um aparelho de GPS, calculava-se a distância das trilhas com um pedômetro e o tamanho da queda foi medido de forma manual, lançando uma corda de $100 \mathrm{~m}$ do topo a base.

Os trabalhos de gabinete envolveram a análise, tratamento e integração dos dados primários e secundários obtidos, gerando fotografias, mapas, croquis, entre outros, que contribuíram para o entendimento e representação do objeto de estudo.

O mapa de localização das quedas d'água foi realizado através de dois softwares: AutoCad 2004 e ArcView Gis 3.1. No primeiro programa foi digitalizada a base cartográfica do município de Indianópolis, com a localização da rede de drenagem presente na área de estudo. Posteriormente, essa base foi importada para o segundo programa, no qual foi realizado o georreferenciamento das quedas d'água. 


\section{LOCALIZAÇÃO GEOGRÁFICA}

O Salto de Furnas está localizado no Ribeirão das Furnas, entre os municípios de Indianópolis e Araguari, oeste de Minas Gerais, na região do Triângulo Mineiro (mapa 01).

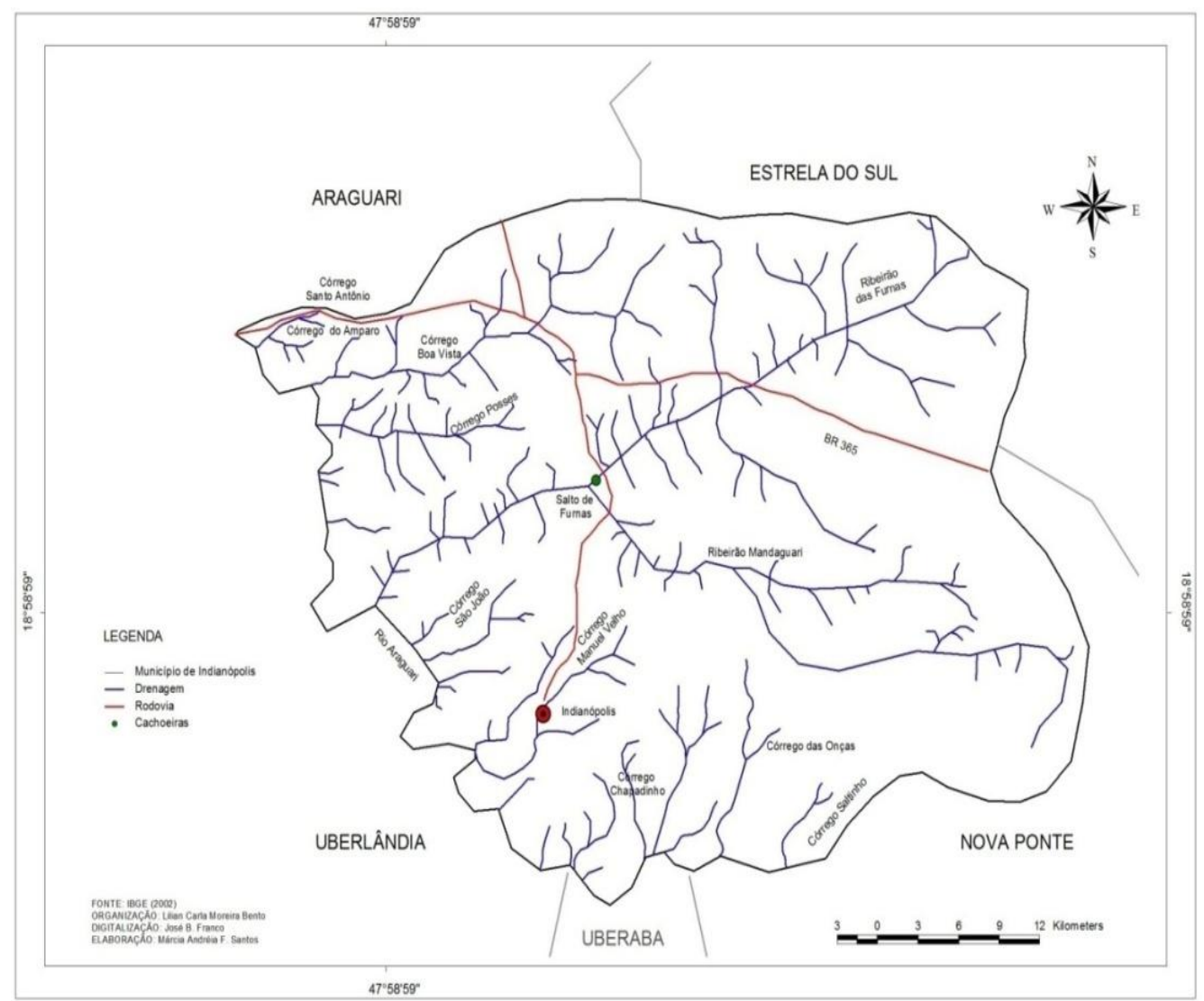

Mapa 01: Localização do Salto de Furnas.

Esta queda d'água é apenas uma das vinte localizadas e mapeadas no município de Indianópolis e foi escolhida neste estudo devido a sua facilidade de acesso, localização estratégica entre os municípios de Uberlândia, Araguari e Indianópolis e também pela sua diversidade litoestratigráfica, o que permite compreender grande parte da história geológica da região Sudeste.

Está distante $10 \mathrm{~km}$ de Indianópolis e para chegar a base do salto é preciso percorrer uma trilha de 900 metros, de fácil acesso, porém em alguns pontos é bastante inclinada, exigindo mais preparo físico do turista. Além disso, 
ao longo da trilha existem alguns pontos estratégicos onde é possível visualizar o relevo, em específico os patamares formados pelos derrames de basalto.

\section{ASPECTOS DA GEODIVERSIDADE REGIONAL E LOCAL}

O município de Indianópolis está localizado na porção nordeste da Bacia Sedimentar do Paraná, apresentando rochas vulcano-sedimentares que se assentam de forma discordante sobre rochas do pré-Cambriano do Grupo Araxá e recobrindo as rochas mais antigas e localizadas nas partes superiores do relevo encontra-se a Cobertura Cenozóica - (mapa 02).
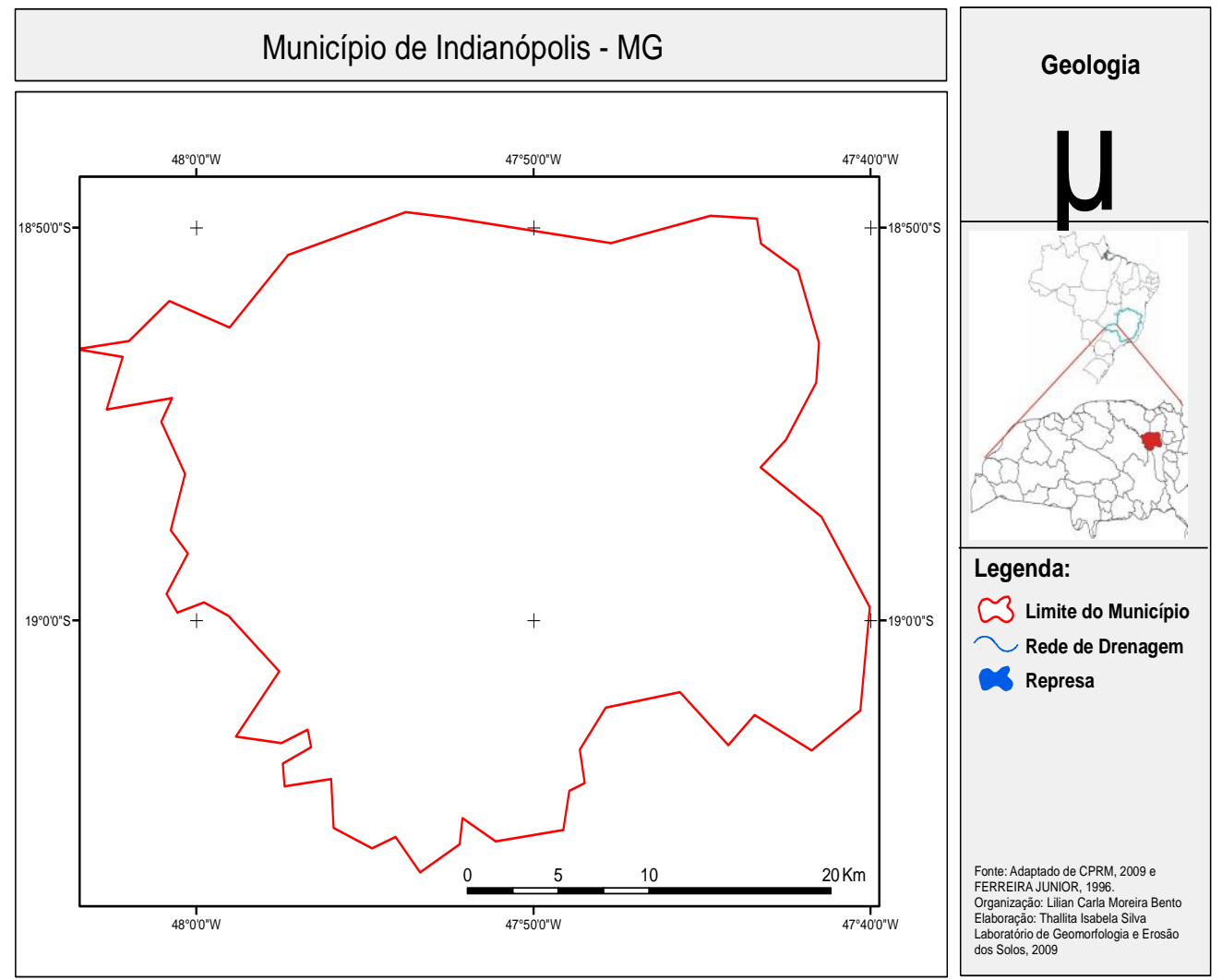

Mapa 02: Unidades Geológicas de Indianópolis.

Considerando o tempo geológico, o GRUPO ARAXÁ compreende rochas pré-Cambrianas de idade mais antiga da região, aparecendo junto às margens do rio Araguari e trechos inferiores dos seus afluentes, tais como 
gnaisses, micaxistos e quartzitos que apresentam-se bastante alteradas por ação tectônica e potencial erosivo das águas.

De acordo com Barbosa et al (1970 apud PINA; PIRES; OLIVEIRA, 2008, p. 2-3), este grupo compreende "[...] metamorfitos de fácies epidotoanfibolito, consistindo essencialmente de micaxistos e quartzitos, com intercalações de anfibolitos. O nome do grupo foi dado por Barbosa (1955) durante os estudos realizados no Triângulo Mineiro, nos arredores de Araxá".

Em Indianópolis foi visualizado apenas o gnaisse, rocha metamórfica que se apresenta na região, de acordo com o Radambrasil (1993), bastante quartzosa, de cor predominantemente cinza, com variedades esbranquiçadas e rosadas em rochas mais quartzosas e graníticas.

Essas rochas foram encontradas aflorando apenas em algumas quedas (no seu perfil ou logo abaixo no curso d'água): Salto do Mirandão, Salto de Furnas, Saltinho do Miranda, Saltinho Santo Antônio, Saltinho das Onças, Cachoeira do Saltinho e Cachoeira do Tembé.

Apesar de não aparecer no mapa 02, a Formação Botucatu foi encontrada em alguns cursos d'água sobre rochas do Grupo Araxá, na forma intertrapeana. Foi encontrada em diversos perfis de quedas d'água, sendo "[...] constituída essencialmente por arenitos com estratificação cruzada, planar ou acanalada, de médio a grande porte (campos de dunas eólicas) com raras intercalações de arenitos com estratificação plano-paralela" (ASSINE; PIRANHA; CARNEIRO, 2004, p. 90).

$\mathrm{Na}$ área de estudo foi encontrado o arenito Botucatu sob duas condições: intertrapeano, aparecendo em locais com espessuras maiores (Salto do Mirandão) e em espessuras menores, na forma de lente mais fina que é difícil sua visualização e também na forma de lajes.

A Formação Serra Geral foi encontrada sobre rochas do Grupo Araxá ou da Formação Botucatu e corresponde a uma sucessão de "[...] derrames de basalto toleíticos, creme-amarronzados, cinza-escuro e esverdeado, textura predominantemente afanítica, amigdaloidal no topo, e raramente vitrofírica. Presença de intertrapes areníticos (...)" (RADAMBRASIL, 1983, p. 30). 
As rochas basálticas desta formação apresentam algumas descontinuidades internas, como vesículas, amígdalas e diáclases, relacionada com a composição diferenciada do magma e com o tempo que a lava levou para se resfriar.

Leinz e Amaral (1985) propõem uma metodologia de identificação e individualização dos derrames com base na sua morfologia: a base do derrame tem constituição vítrea e geralmente é preenchida por vesículas devido ao rápido resfriamento, passando gradativamente para uma área de basaltos microcristalinos ricos em diáclases verticais. Chegando ao topo é possível encontrar uma camada de basaltos de granulação vesicular e de diáclases horizontais e, por fim, é comum existir mais uma camada de basalto vesicular, muitas vezes misturado com arenito.

Segundo a Cemig (1988) nos estudos ambientais para implantação da Usina de Miranda foram identificados cinco derrames de basalto na região do Triângulo Mineiro, no entanto, em Indianópolis encontrou-se nos perfis das quedas d'água o máximo de três derrames.

Em Indianópolis encontramos em algumas quedas d'água o basalto amigdaloidal preenchido por cloritas de coloração esverdeada, como observase na amostra retirada no Saltinho das Onças, e locais onde o basalto está intensamente fraturado, tanto na horizontal como na vertical.

E no topo das chapadas, encobrindo as rochas mais antigas aparece a Cobertura Inconsolidada do Cenozóico, formada por sedimentos mais jovens, inconsolidados e, geralmente, por seixos de quartzo, quartzitos e sílex, com cimentação por óxido de ferro (FELTRAN FILHO, 1997).

De acordo com o Radambrasil (1983) esta cobertura abrange depósitos eluviais e colúvio-aluviais laterizados e os seixos são oriundos dos Grupos Araxá, São Bento e Bauru, mediante processos erosivo-deposicionais (FERREIRA JÚNIOR, 1996) e divide-se em Detrito-Lateríticas Terciárias e Detrito-Lateríticas Terciárias e Quaternárias Indiferenciadas, esta última sendo denominada por Ferrari (1989) de Formação Nova Ponte.

Considerando os aspectos geomorfológicos, o município está inserido no conjunto de relevo do oeste mineiro, onde se inserem as chapadas, sendo que 
o "o quadro paisagístico das chapadas é definido pela presença de relevo suave ondulado com topos planos, com vertentes longas e convexizadas" (FELTRAN FILHO, 1997, p. 152).

Segundo Feltran Filho (1997) e Soares (2008), a origem e evolução das Chapadas estão relacionadas, principalmente, com as oscilações climáticas e epirogenéticas ocorridas no Cenozóico. Inicialmente, o clima mais úmido teria favorecido a erosão vertical, com aprofundamento dos vales e a erosão horizontal promovendo um desnível topográfico, havendo uma reorganização da rede de drenagem, com a instalação dos principais rios da região em falhamentos pré-existentes.

No Plioceno o clima, mais árido e frio e uma nova reativação tectônica rebaixaram o lençol freático, fazendo com que os canais fluviais aprofundassem ainda mais seus leitos. Já no Pleistoceno o clima semi-árido e a ocorrência de chuvas torrenciais promoveram a dissecação das

[...] rochas mais resistentes originando relevos residuais de topos planos, como são as chapadas, ao passo que a meteriorização física atuando nos interflúvios, ocasionou o aparecimento de residuais rebaixados, como são as chamadas "serras" do Parafuso, do Talhado e de São Lourenço, nos interflúvios dos rios Grande e Tijuco/Prata" (FELTRAN FILHO, 1997, p. 187).

E a partir do Holoceno até os dias atuais predomina o clima tropical com relevante alternância entre épocas secas e úmidas, promovendo a aceleração do intemperismo químico, a verticalização do relevo, a erosão superficial, a denudação, a lixiviação, tudo isso contribuindo para a formação de camadas lateríticas e para aumentar a espessura dos solos aqui originados.

Ferreira (2005) e Baccaro et al (2001), em seus estudos geomorfológicos no Triângulo Mineiro e Alto Paranaíba, estabeleceram unidades morfoestruturais e morfoesculturais para toda essa região. Especificamente para nossa área de estudo, inferi-se que Indianópolis está inserida na morfoestrutura da Bacia Sedimentar do Paraná, num conjunto de relevo denominado por Ab'Saber (1977) de Domínio dos Chapadões 
recobertos por cerrados e penetrados por florestas galeria ou Planaltos e Chapadas da Bacia Sedimentar do Paraná (RADAMBRASIL, 1983), apresentando três unidades morfoesculturais: Planalto Tabular, Planalto Dissecado e Canyon do Araguari (mapa 03).

- Canyon do Rio Araguari: segundo Baccaro (1991) corresponde a borda da Chapada Araguari-Uberlândia, estendendo-se até os rios Paranaíba e Grande.

Vem sendo dissecada por vários afluentes e apresenta vertentes abruptas, além disso, as altimetrias variam de 500 a $700 \mathrm{~m}$, a declividade de $25^{\circ}$ a $40^{\circ}$ e a maior parte desta unidade encontra-se assentada sobre as rochas do Grupo Araxá.

Os solos são, em sua maioria, Podzólico Vermelho-Amarelo Distrófico e Eutrófico e Cambissolo Álico e Distrófico e é muito comum nesta unidade a presença de pastagens e áreas de preservação ambiental.
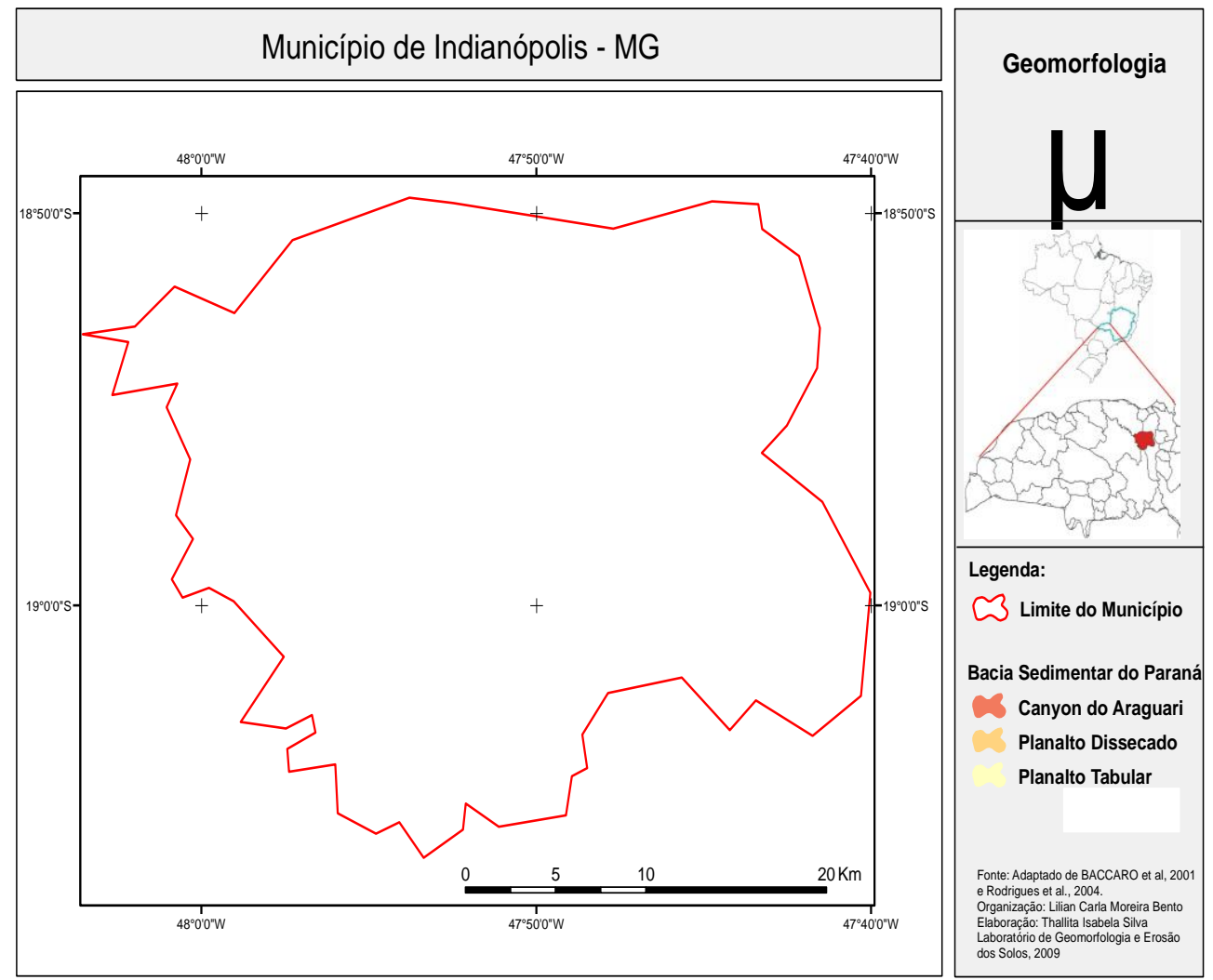

Mapa 03: Unidades morfoesculturais do município de Indianópolis. 
- Planalto Dissecado: tem como característica principal o modelado do tipo denudacional de topo plano ou tabular com formas mais ou menos dissecadas a medida que aproxima-se dos vales dos rios.

A altitude varia de 700 a $900 \mathrm{~m}$ e a geologia predominante são os basaltos aflorando nos fundos de vale e a Formação Nova Ponte aparecendo nos topos. Os solos do tipo Cambissolo, Latossolo, Terra-roxa estruturada e litólicos predominam nesta unidade, condicionando o uso do solo com pastagens, reflorestamento e culturas de café.

Nesta unidade é comum o aparecimento de cachoeiras e corredeiras e tal fato pode ser explicado pela sua localização "[...] a montante de rupturas estruturais (knick points) nos derrames da Formação Serra Geral" (BACCARO et al, 2001, p. 122).

- Planalto Tabular: tem por característica principal as formas de relevo do tipo denudacional tabular, com modelados suavemente ondulados. Referente à geologia predomina a Formação Marília que é parcialmente coberta por sedimentos do Cenozóico, porém, em Indianópolis só visualizou-se a Formação Nova Ponte.

Os solos predominantes são Latossolos Vermelho-Escuro e VermelhoAmarelo de texturas argilosas o que aliado a um modelado de declividade suave favorece o uso do solo pela agricultura, destacando-se as grandes lavouras de soja e café, além dos reflorestamentos.

Com altitudes variando entre 900 e 1000 m é comum o aparecimento de veredas. Esses locais "são vales amplos com fundo plano, com presença de sedimentos colúvio-aluviais compostos por argilas e materiais orgânicos, em ambiente hidromórfico. São recobertas por vegetação de gramíneas e ciperáceas, com grande destaque para a palmeira buriti" (LIMA, 1996, p. 30$31)$.

\section{O SALTO DE FURNAS E SEU POTENCIAL PARA O GEOTURISMO}

Não é fácil encontrar pesquisas e trabalhos concluídos sobre a conceituação, gênese e evolução de quedas d'água e os que existem ainda 
apresentam algumas lacunas, evidenciando a necessidade de realização de mais pesquisas nesta área que atualmente tem recebido bastante atenção em virtude da criação e expansão do geoturismo.

Segundo Christofoletti (1981, p. 241) quedas d'água são "[...] locais onde a água do rio cai de maneira subvertical, deslocando-se da rocha do leito" e tal deslocamento se dá em função da "[...] existência de um degrau no perfil longitudinal do curso d'água" (GUERRA, 1994 apud JATOBÁ; LINS, 1998).

A primeira condição para o surgimento de uma queda d'água é a existência de um degrau no perfil longitudinal do curso d'água, isto é, presença de um desnível topográfico que pode ser na ordem de dezenas ou mesmo centenas de metros de queda.

No caso do Salto de Furnas a explicação para o desnível topográfico onde está a queda d'água foi encontrada na evolução geológica e geomorfológica da região Sudeste.

A partir do Cretáceo teve início na região Sudeste uma evolução morfotectônica que reativou antigas falhas e fraturas, direcionando os cursos d'água através de extensos e diversos lineamentos tectônicos.

Estes lineamentos correspondem ao conjunto de fraturas de uma região, sendo uma "[...] feição linear simples ou composta da superfície, cujas partes são alinhadas de modo retilíneo ou levemente curvilíneo e que difere distintamente dos padrões de feições adjacentes e presumivelmente reflete um fenômeno subsuperficial" (O'LEARY et al., 1976 apud CARRARO; MEXIAS, p. 3).

Os lineamentos do município de Indianópolis apresentam direção nordeste-sudeste, sendo perpendiculares ao lineamento maior, por onde corre o rio Araguari, que tem direção noroeste-sudeste, todos estes influenciando o sistema de drenagem da região, direcionando os cursos d'água e, consequentemente, propiciando o aparecimento de quedas d'água.

E no Cenozóico foram comuns as oscilações climáticas e epirogenéticas que contribuíram para a ocorrência da erosão vertical e horizontal, o que provocou um aprofundamento dos vales, desníveis topográficos e 
reorganização da rede de drenagem, fazendo com que os principais rios da região Sudeste se instalassem em falhamentos pré-existentes.

O Salto de Furnas, assim como as outras quedas encontradas no município de Indianópolis, é uma queda d'água de origem erosiva e foram suas diferentes litoestratigrafias as responsáveis pela sua evolução, uma vez que se tem uma formação litológica mais resistente cobrindo camadas mais fracas. Este é o caso do arenito da Formação Botucatu encontrado sob o basalto da Formação Serra Geral, fazendo com que a formação menos resistente, neste caso o arenito, comece a ser erodido, deixando a camada superior, o basalto, sem sustentação, provocando a queda de blocos num processo conhecido por erosão regressiva ou remontante. Neste tipo de situação há a formação de um sulco, denominado de canhão, que pode ser verificado no perfil da queda do Salto de Furnas e também ao seu redor, acompanhando a linha de erosão.

O Salto de Furnas tem $40 \mathrm{~m}$ de queda e ao longo do seu perfil identificase, da base para o topo, as seguintes litologias: gnaisse, arenito e basalto (figura 03). 


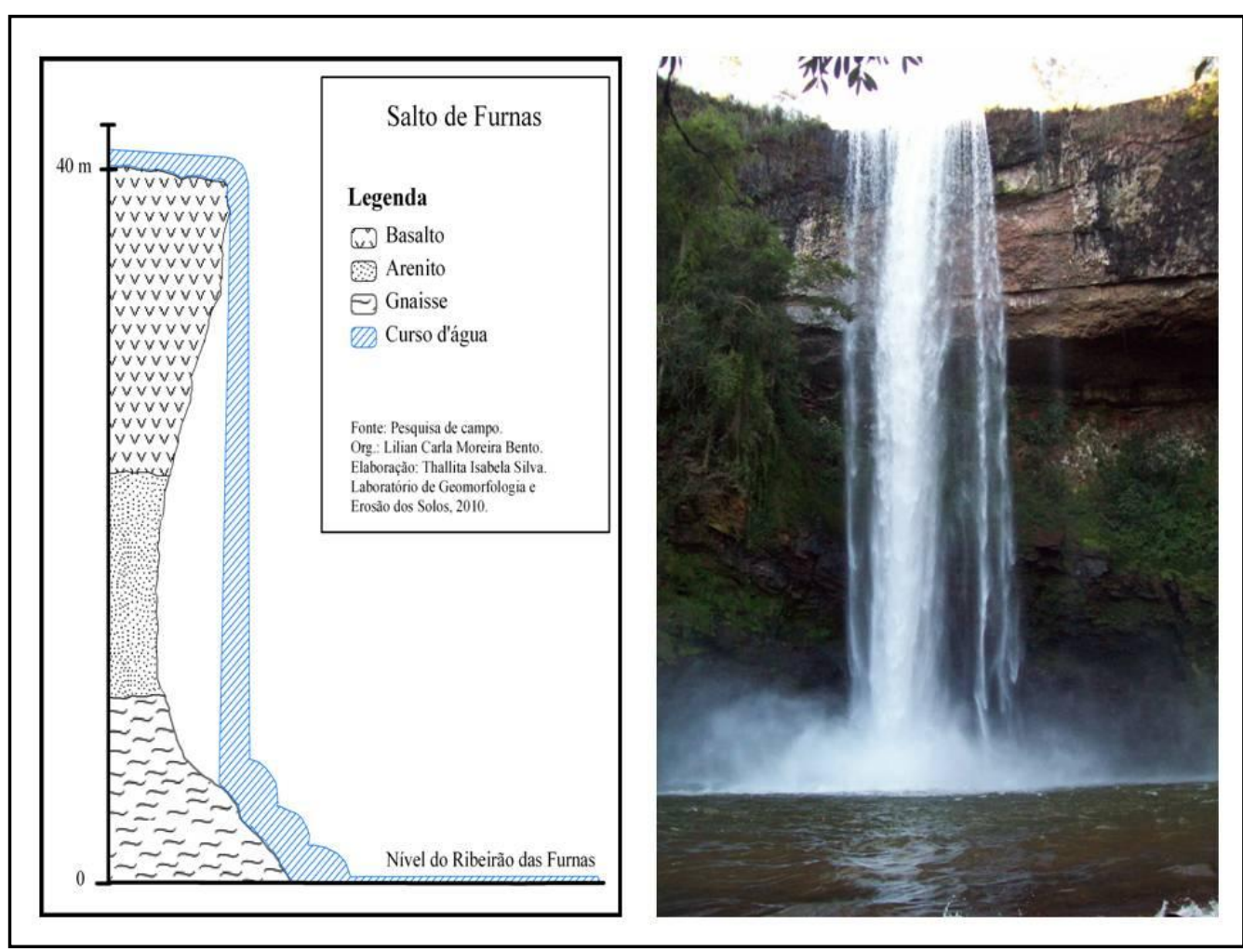

Figura 03: Perfil litoestratigráfico e fotografia do Salto de Furnas / Org. e autor: Bento, 2009.

Há outros fatores que contribuem para a evolução de uma queda d'água, como a existência de diferentes níveis de fraturas no basalto que potencializa a ação erosiva de diversos elementos, como água e raízes, facilitando o desalojamento e desagregação das rochas, tornando-as mais susceptíveis à atuação de outros processos de alteração física e/ou química.

No Salto de Furnas existem ao lado da queda locais onde as raízes das árvores, facilitado pela existência de fraturas no basalto, estão penetrando nas rochas, contribuindo para sua desagregação e decomposição.

Através da identificação das litologias encontradas no perfil dessa queda é possível associá-las aos seus respectivos grupos e/ou formações geológicas e à era em que foram formadas, oportunizando ao turista um apanhado rápido da evolução geológica da região.

Observando as rochas encontradas no Salto de Furnas compreende-se parte da história geológica entre o Pré-Cambriano e o Mesozóico, eras associadas, respectivamente, ao Grupo Araxá (gnaisses) e Grupo São Bento 
(arenitos e basaltos), pois as rochas e também os fósseis são os registros, as testemunhas de todos os processos e/ou acontecimentos do nosso planeta.

\section{CONSIDERAÇÕES FINAIS}

O Salto de Furnas em seus $40 \mathrm{~m}$ de queda expõe diferentes litoestratigrafias que permite remontar milhões de anos, passando do PréCambriano ao Mesozóico, possibilitando o entendimento de parte da história da geológica da região Sudeste, bem como de sua evolução geomorfológica e identificação de variados agentes erosivos atuantes na gênese e evolução das quedas d'água.

Considerando estas características depreendemos que este salto pode ser utilizado como atrativo do geoturismo, já que através de sua apreciação e interpretação é possível compreender a geologia e relevo locais e sua integração num contexto maior que é a evolução do planeta.

Importante ressaltar que o Salto de Furnas está situado numa área ainda bem preservada, permitindo uma interface do geoturismo com o ecoturismo, proporcionando aos turistas uma visão conjunta dos aspectos bióticos e abióticos da paisagem, isto é, da geodiversidade e da biodiversidade.

Vale salientar que existem outras quedas no município de Indianópolis que podem ser aproveitadas turisticamente, entretanto, é preciso que todas elas sejam inseridas num projeto de planejamento turístico, visando a sua gestão e exploração ordenadas, de forma que estes locais de grande beleza cênica e importância geocientífica e ecológica sejam conservados e o geoturismo, entre outros segmentos turísticos, possa se transformar de fato em um instrumento de geoconservação.

Menciona-se ainda que a questão da sustentabilidade tão almejada na atualidade exige a implantação do geoturismo e segmentos turísticos afins mediante um processo que envolva a população local, principalmente a população rural que possuem quedas em suas propriedades, contribuindo para a sua melhoria da qualidade de vida. 
É preciso que o poder público local envolva a comunidade, criando programas de capacitação e, principalmente, educando, conscientizando e motivando-a a investir nesta área, o que em continuidade com as outras atividades desenvolvidas agregaria ainda mais renda à família, o que não deixa de ser um forte estímulo para a busca da conservação destas áreas.

Em seu trabalho sobre relevância e uso do patrimônio geomorfológico em Portugal, Silva e Pereira (2009, p. 277), reforçam a proposta acima, afirmando que "o turismo é uma mais-valia para qualquer região [...] e a rentabilização dos vastos recursos ambientais e patrimoniais contemplando a vertente turística é [...] um dos eixos de intervenção para a promoção do desenvolvimento local".

\section{AGRADECIMENTOS}

Ao CNPq pela bolsa de mestrado e a Capes pelo financiamento do projeto PROCAD 067/2007 e pela bolsa de doutorado.

\section{REFERÊNCIAS}

ARAÚJO, E. L. da S. Geoturismo: conceptualização, implementação e exemplo de aplicação ao Vale do Rio Douro no Setor Porto-Pinhão. 2005. 219 f. Dissertação (Mestrado em Ciências do Ambiente) - Escola de Ciências, Universidade do Minho, Minho, 2005.

BARRETO, J. M. C. Potencial geoturístico da região de Rio de Contas - Bahia - Brasil. 2007. 164 f. Dissertação (Mestrado em Geologia) - Instituto de Geociências, Universidade Federal da Bahia, Salvador, 2007.

BINDA, A. L.; CAMARGO FILHO, M. Aspectos litoestratigráficos do Salto São Francisco, Guarapuava-PR. In: WORKSHOP REGIONAL DE GEOGRAFIA E MUDANÇAS AMBIENTAIS, 1. Anais... p. 15 - 22. Disponível em: http://www.unicentro.br . Acesso em: Jam.2009.

BRANCO, P. de M. Breve história da Terra. Disponível em: http://www.cprm.gov.br. Acesso em: jan. 2009.

BRILHA, J. Patrimônio geológico e geoconservação - a conservação da natureza na sua vertente geológica. Braga: Palimage, 2005. 190 p.

CARRARO, C. C.; MEXIAS, A. S. Imagens de sensoriamento remoto no mapeamento de lineamentos do centro do Escudo Sul-Rio-Grandense. 8 p. Disponível em: http://www.obinpe.br. Acesso em: mai. 2009. 
CUMBE, A. N. F. O patrimônio geológico de Moçambique: proposta de metodologia de inventariação, caracterização e avaliação. 2007. $273 \mathrm{f}$. Dissertação (Mestrado em Patrimônio Geológico e Geoconservação) Departamento de Ciências da Terra, Universidade do Minho, Braga, 2007. Disponível em: http://www.repositorium.sdum.uminho.pt. Acesso em: out. 2009.

CHRISTOFOLETTI, A. Geomorfologia fluvial. São Paulo: Edgard Blucher, 1981. $313 \mathrm{p}$.

CPRM. Mapa geodiversidade do Brasil. Brasília: CPRM, 2006. 68 p.

DELBONI, H.; ROTA, P. S. Geografia para todos - a Terra como morada. São Paulo: Scipione, 2003. 215 p.

FORTE, J. P. Patrimônio geomorfológico da Unidade Territorial de Alvaiázere: inventariação, avaliação e valorização. 2008. 295 f. Dissertação (Mestrado em Geografia) - Departamento de Geografia, Universidade de Lisboa, Lisboa, 2008.

JATOBÁ, L.; LINS, R. C. Introdução à Geomorfologia. 2 ed. Recife: Bagaço, 1998. $150 \mathrm{p}$.

LEINZ, V.; AMARAL, S. E. do. Geologia Geral. 13 ed. São Paulo:Companhia Editora Nacional, 1988. $487 \mathrm{p}$.

LEITE DO NASCIMENTO, M. A.; RUCHKYS, U. A. de; MANTESSO-NETO, V. Geoturismo: um novo segmento do turismo no Brasil. Global Tourism, [s.I.], v. 3, n. 2, Nov. 2007. Disponível em: http://www.periodicodeturismo.com.br. Acesso em: 01 mar. 2008.

. Geodiversidade, geoconservação e geoturismo - trinômio importante para a proteção do patrimônio geológico. São Paulo: Sociedade Brasileira de Geologia, 2008. 84 p.

; SHOBBENHAUS, C.; MEDINA, A. I. de M. Patrimônio geológico: turismo sustentável. In: SILVA, C. R. da (Ed.). Geodiversidade do Brasil conhecer o passado para entender o presente e prever o futuro. [s.I.]: CPRM, 2009. p. $147-162$.

LIMA, F. F. de. Proposta metodológica para a inventariação do Patrimônio Geológico Brasileiro. 2008. 103 f. Dissertação (Mestrado em Patrimônio Geológico e Geoconservação) - Escola de Ciências, Universidade do Minho, Minho, 2008.

MOREIRA, J. C. Patrimônio geológico em Unidades de Conservação: atividades interpretativas, educativas e geoturísticas. 2008. 428 f. Tese (Doutorado em Geografia) - Centro de Filosofia e Ciências Humanas, Universidade Federal de Santa Catarina, Santa Catarina, 2008. 
PANIZZA, M.; PIACENTE, S. Geomorphosites and Geotourism. Revista Geográfica Acadêmica, v. 2, n. 1, 2008, p. 5 - 9. Disponível em: $<$ http://geograficaacademica.webng.com>. Acesso em: jan. 2010.

PEREIRA, D. et al. Inventariação temática do patrimônio geomorfológico português. Geomorfologia - ciência e sociedade, Coimbra, v. 3, p. 155 - 159, 2006. Resumo expandido do trabalho apresentado no Congresso Nacional de Geomorfologia, 2.

.; PEREIRA, D.; ALVES, I. C. Patrimônio geomorfológico: da actualidade internacional do tema ao caso português. In: CONGRESSO DE GEOGRAFIA PORTUGUESA, 5, 2004, Minho. Anais... Minho: APGEO, 2004. $18 \mathrm{p}$.

PEREIRA, P. J. da S. Patrimônio geomorfológico: conceptualização, avaliação e divulgação. Aplicação ao Parque Natural de Montesinho. 2006. 395 f. Tese (Doutorado em Ciências) - Escola de Ciências, Universidade do Minho, Minho, 2006.

RADAMBRASIL. Levantamento de Recursos Naturais. Rio de Janeiro, Folha SE., 22, Goiânia, 1983. V. 31.

RUCHKYS, U. A. de. Patrimônio geológico e geoconservação do Quadrilátero Ferrífero, Minas Gerais. 2007. 233 f. Tese (Doutorado em Geociências) Instituto de Geociências, Universidade Federal de Belo Horizonte, Belo Horizonte, 2007.

SILVA, F. R. A paisagem do Quadrilátero Ferrífero, MG: Potencial para o uso turístico da sua geologia e geomorfologia. 2007. 144 f. Dissertação (Mestrado em Geografia) - Departamento de Geografia, Universidade Federal de Minas Gerais, Belo Horizonte, 2007. Disponível em: http://www.bibliotecadigital.ufmg.br. Acesso em:20 ago. 2008.

SILVA, J. R. B. da; PERINOTTO, J. A. da J. O geoturismo na geodiversidade de Paraguaçu Paulista como modelo de geoconservação das estâncias. Global Tourism, [s.I.], v. 3, n. 2, Nov. 2007. Disponível em: http://www.periodicodeturismo.com.br. Acesso em: 01 mar. 2008.

Contribuições da geologia para o desenvolvimento sustentável do turismo no município da Estância Turística de Paraguaçu Paulista (SP). 2004. 118 f. Dissertação (Mestrado em Geociências e Meio Ambiente) - Instituto de Geociências e Ciências Exatas, Universidade Estadual Paulista, Rio Claro, 2004.

SILVA, P.; PEREIRA, D. Relevância e uso do patrimônio geomorfológico: o caso do concelho de Vieira do Minho. In: CONGRESSO NACIONAL DE GEOMORFOLOGIA, 6., 2009, Braga. Anais... Braga: APGEOM, 2009, p. 273278. 